\title{
MECHANICAL PROPERTIES AND STRAIN HARDENING BEHAVIOUR OF MAGNESIUM ALLOYS AND COMPOSITES
}

Selected magnesium alloys and composites with magnesium alloy matrix were deformed at temperatures between room temperature and $300{ }^{\circ} \mathrm{C}$ at constant strain rate. The testing temperature influences significantly the deformation behaviour of the al/loys. The flow stress decreases with increasing temperature. The work hardening rate decreases with stress (strain) and temperature. Above about $200{ }^{\circ} \mathrm{C}$, a dynamic balance between hardening and softening is observed. Stress relaxation tests were performed to identify thermally activated dislocation motion. The main thermally activated process is very probably the glide of dislocation in non-basal planes. The internal component of the applied stress decreases significantly with increasing temperature.

\section{Introduction}

Magnesium alloys, the lightest structural metallic materials, have been considered for many applications including automotive and other transport industries. Most commercial magnesium alloys exhibit a relatively high specific strength (the strength/density ratio), comparable with moderate strength aluminium alloys, and high specific stiffness at room temperature. However, the magnesium alloys possess poor mechanical properties at temperatures above about $150{ }^{\circ} \mathrm{C}$. There are many possibilities how to increase the strength of a metallic material. The mechanical properties of magnesium alloys may be influenced by one or more of the well known strengthening mechanisms - solid solution hardening, precipitation strengthening, dispersion hardening, grain-size refinement. The shape and nature of precipitates and dispersoids have a significant effect on the microstructure, which controls the material behaviour. The addition of ceramic or graphite reinforcements - fibres and/or particles - into magnesium alloys can significantly improve their physical, mechanical and damping behaviour [1]. It is obvious that research on magnesium alloys focusing on mechanical properties has attained an increasing interest during last decades.

The mechanical properties of magnesium alloys were investigated using specimens prepared by different production processes. One of the common casting methods is squeeze casting. During squeeze casting, the molten metal is poured to a preheated die and then the upper half closes the die under press. The advantage of squeeze casting is a low porosity. Wrought magnesium alloys are very often produced by hot rolling and extrusion. Over the last decade, severe plastic deformation (SPD) techniques were used to prepare ultrafine-grained materials [2]. Among these, equal channel angular pressing (ECAP) refines the grain structure of materials to submicrometer level and the material shape does not change.
Recent results have shown that processing of some magnesium alloys by ECAP introduces a superplastic capability. The wrought alloys exhibit texture that influences the mechanical properties. There is a difference in the deformation behaviour if a specimen is deformed in tension or in compression and/or the mechanical properties are different if specimens are deformed in different direction.

The deformation behaviour of magnesium alloys and magnesium-based composites were investigated over a wide temperature range - very often between room temperature and $300-400{ }^{\circ} \mathrm{C}$. At higher temperatures, dynamic recovery or dynamic recrystallisation may influence the deformation behaviour. Investigations of the effect of temperature on the flow behaviour are important for applications and/or for estimation of suitable forming conditions. In order to understand the flow behaviour of a material, it is important not only to estimate the experimental values - the characteristic of deformation - but also to determine dislocation mechanisms during deformation.

The aim of the present paper is to give an overview on the deformation behaviour of some magnesium alloys at different temperatures and to describe dislocation mechanisms that control the behaviour. Stress relaxation tests will be used in order to describe possible dislocation mechanisms during deformation of alloys prepared by different processing techniques.

\section{Stress relaxation}

It is widely accepted that the stress necessary for the dislocation motion in polycrystals can be divided into two components [3]

\footnotetext{
* Pavel Lukac, Zuzanka Trojanova

Department of Physics of Materials, Faculty of Mathematics and Physics, Charles University, Praque, Czech Republic,

E-mail: lukac@met.mff.cuni.cz
} 


$$
\sigma=\sigma_{i}+\sigma^{*}
$$

Here $\sigma_{i}$ is the internal (athermal) stress, resulting from longrange stresses impeding the plastic flow. Contribution of dislocation to this internal stress component may be expressed as

$$
\sigma_{i}=\alpha_{1} G b \rho_{t}^{1 / 2}
$$

Here $G$ is the shear modulus, $\alpha_{1}$ is a constant describing interaction between dislocations, $b$ is the Burgers vector of dislocations and $\rho_{t}$ is the total dislocation density. The effective stress $\sigma^{*}$ acts on dislocations during their thermally activated motion when they overcome short range obstacles.

In a stress relaxation (SR) test, the specimen is deformed to a certain stress $\sigma_{0}$ and then the testing machine is stopped and the stress is allowed to relax [4]. The stress decreases with time $t$. The specimen can be again reloaded to a higher stress (load) and the SR test may be repeated. The stress decrease with time during the SR test can be described by the following equation [5]

$$
\Delta \sigma(t)=\sigma(0)-\sigma(t)=\alpha \ln (\beta t+1)
$$

where $\sigma(0) \equiv \sigma_{0}$ is the stress at the beginning of the stress relaxation at time $t=0, \beta$ is a constant and

$$
\alpha=\frac{k T}{V} .
$$

Here $V=b d L$ is the activation volume where $b$ is the Burgers vector, $d$ is the obstacle width and $L$ of the mean length of dislocation segments between obstacles.

The stress relaxation technique has been demonstrated to be a useful method for estimating the activation volume and the both stress components. The components of the applied stress can be estimated using the method of $\operatorname{Li}[6,7]$. The stress relaxation curve should be fitted to the power law function in the following form

$$
\sigma-\sigma_{i}=[a(m-1)]^{\frac{1}{1-m}}\left(t+t_{0}\right)^{\frac{1}{1-m}}
$$

where $a, t_{0}$ and $m$ are fitting parameters ( $m$ can also be determined from strain rate change experiments). This relation was derived based on dislocation dynamics (a power law relation between dislocation density and stress) assuming that both the internal stress and the density of mobile dislocations are constant during the SR.

\section{Experimental procedure}

In this paper we will focus our selection on magnesium alloys prepared by cast, squeeze casting, hot rolling and equal channel angular pressing. Samples were deformed in tension and compression in an INSTRON testing machine at a constant cross-head speed giving an initial strain rate of $6.7 \times 10^{-5} \mathrm{~s}^{-1}$ over a temperature range of 23 to $300{ }^{\circ} \mathrm{C}$. In some cases, sequential stress relaxation tests were performed along a stress-strain curve. Duration of the SR was $300 \mathrm{~s}$.

\section{Results}

The true stress-true strain curves obtained in tension for the cast AZ31 (Mg-3Al-1Zn) alloy at different temperature are shown in Fig. 1. It can be seen that the flow stress decreases with increasing testing temperature. At a temperature of $300{ }^{\circ} \mathrm{C}$, the flow stress is practically independent of strain, no significant strain hardening is observed. The result indicates that dynamic recovery occurs. Similar flow curves were obtained for the AX41 (Mg-4Al-1Ca) alloy deformed in tension as shown in Fig. 2 [8]. The true stress-true strain curves obtained for compression tests for the AJ51 (Mg-5Al1Sr) alloy at various temperatures are shown in Fig. 3 [8]. The true stress-true strain curves for the AZ31 sheets with the tensile axis parallel $(\mathrm{P})$ and perpendicular $(\mathrm{T})$ to the rolling direction obtained at various temperatures are shown in Fig. 4 [9]. It is possible to conclude for the presented results that a high strain hardening is observed at low temperatures, below about $200{ }^{\circ} \mathrm{C}$. At temperatures higher than about $200-250{ }^{\circ} \mathrm{C}$, the flow stress is low and practically independent of strain. A dynamic balance between hardening and softening occurs. It can also be seen that the strength-

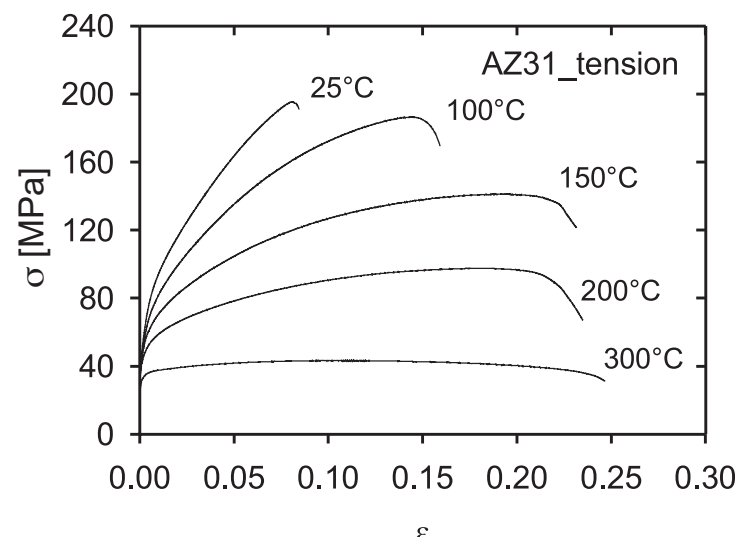

Fig. 1 The true stress-true strain curves of AZ31 measured at different temperatures

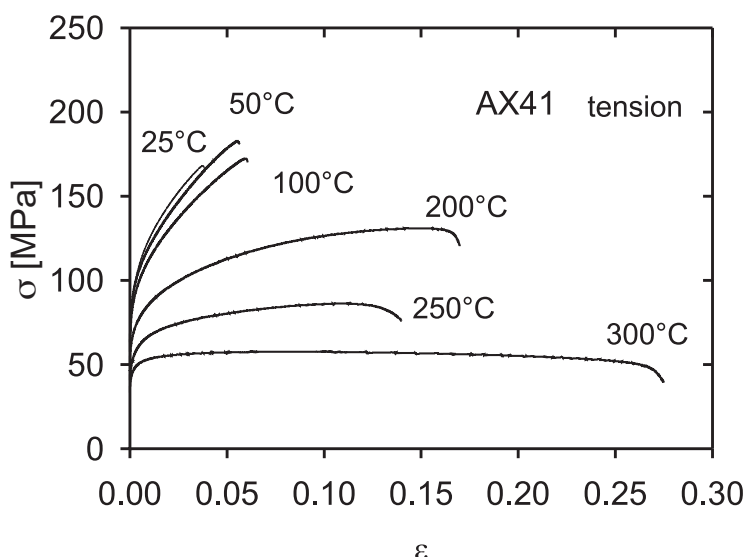

Fig. 2 The true stress-true strain curves of AX41 obtained at various temperatures 


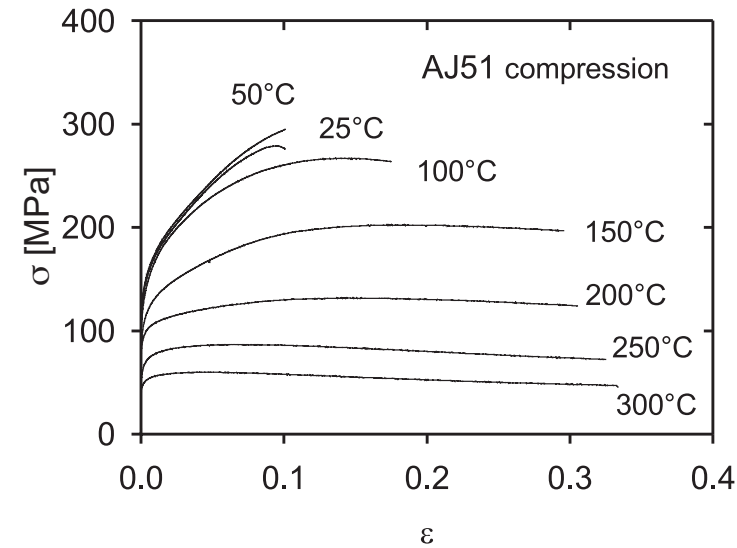

Fig. 3 The true stress-true strain curves of AJ51 measured in compression at various temperatures

ening effect of $\mathrm{Zn}$, as third element, is higher than hardening of $\mathrm{Ca}$ and $\mathrm{Sr}$.

An example of the influence of a processing method on the deformation behaviour is shown in Fig. 5 [10]. The heat-treated samples of cast AZ91 (Mg-9Al-1Zn-0.2Mn) were ECAP processed in a right-angled channel via route $\mathrm{C}$. The number of passes was 1 , 4 and 8 . The total strain rate intensity was $1.15,4.6$. Tensile tests were carried out in a MTS machine at a constant strain rate of $5 \times 10^{-4} \mathrm{~s}^{-1}$ and in the temperature range from $20^{\circ} \mathrm{C}$ to $300{ }^{\circ} \mathrm{C}$. Figure 5 shows the true stress-true strain curves of both as cast and ECAP processed AZ91 samples at different temperatures. The

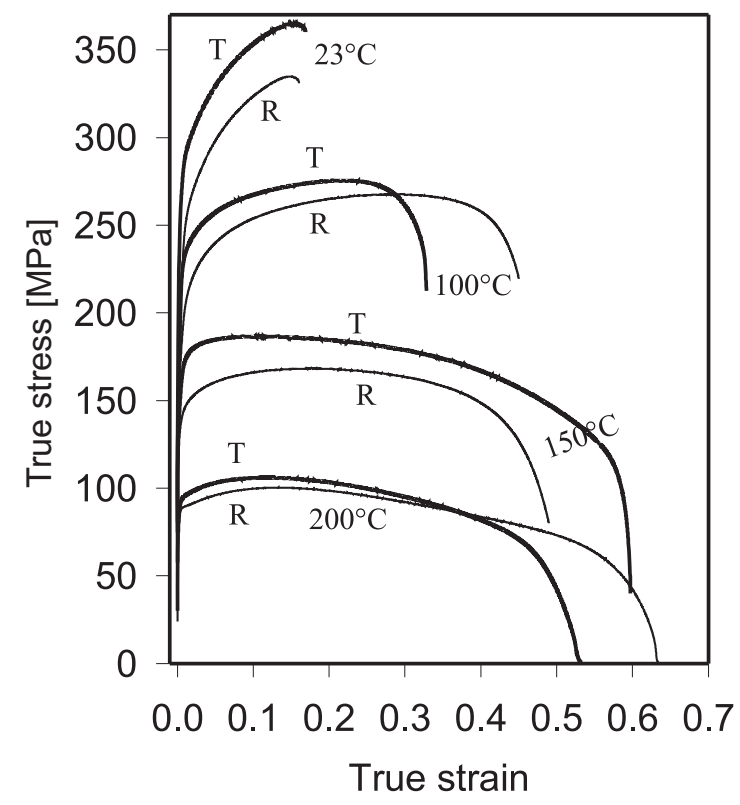

Fig. 4 The true stress-true strain curves of AZ31 sheets measured in tension at various temperatures; the tensile axis was parallel $(P)$ or perpendicular $(T)$ to the rolling direction values of the yield stress at temperatures below $150{ }^{\circ} \mathrm{C}$ for samples after ECAP are higher than those for the cast samples. On the other hand, the yield stress values of samples after ECAP deformed at temeratures above $150{ }^{\circ} \mathrm{C}$ are lower than those for the cast samples as shown in Fig. 6 [10]. Processing by ECAP leads to grain refinement. The grain size of the samples after ECAP processing is about $100 \mathrm{~nm}$; much lower than in as-cast samples. An increase of both the yield stress and maximum flow stress of the samples after ECAP deformed at room temperature is caused by the refinement in grain size. The lower values of the yield stress (and the maximum flow stress) of the samples after ECAP pressing measured at 200 and $300{ }^{\circ} \mathrm{C}$ in comparison with those of the unpressed material indicate some recovery process(es). Rapid grain boundary diffusion is expected at these temperatures. The elongations to failure of the AZ91 alloy after ECAP pressing are much higher than those of the unpressed alloys.

Considerable improvement of the mechanical properties of magnesium alloys can be achieved by addition of ceramic or graphite

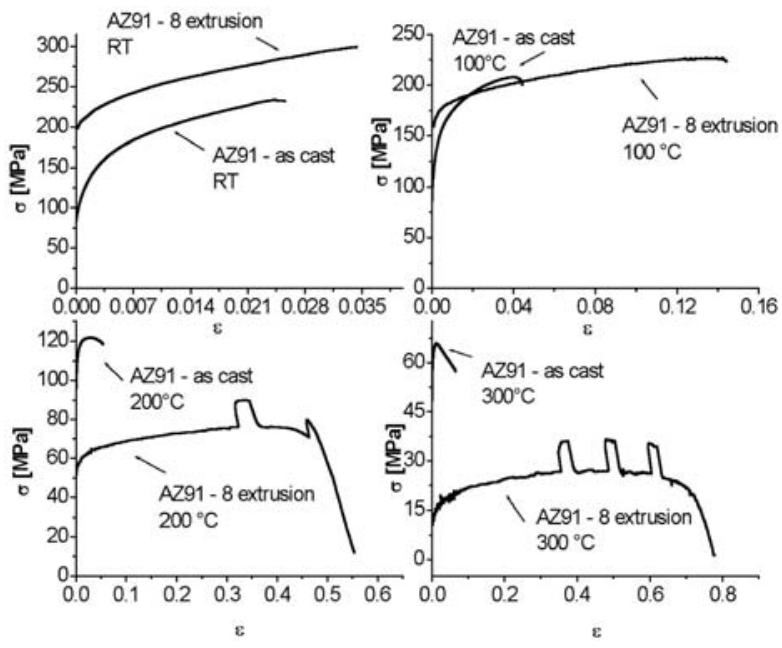

Fig. 5 The true stress-true strain curves measured at different temperatures for cast AZ91 alloy and AZ91 alloy after ECAP processing

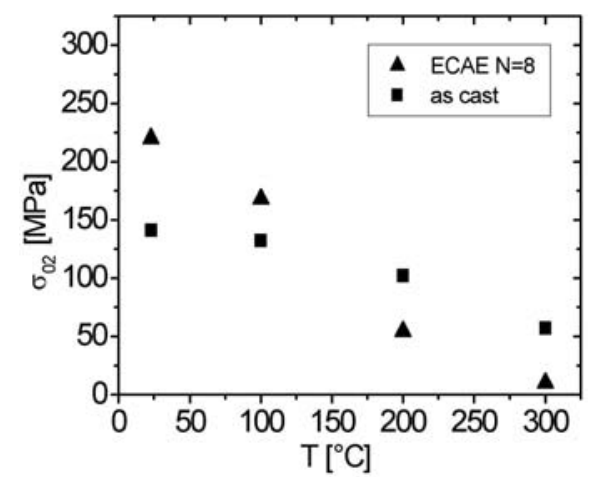

Fig. 6 Temperature dependence of the yield stress of cast AZ91 samples and after ECAP processing 
fibres (or particles). Commercial AX41 alloy was reinforced with short fibres of Sigrafil C40 with a mean diameter of $7 \mu \mathrm{m}$ and a mean length of about $100 \mu \mathrm{m}$. Preform of short fibres exhibited a planar isotropic fibre distribution. Metal matrix composites with a fibre volume fraction of 17 vol. \% were prepared by squeeze casting. Two kinds of composite samples were investigated in compression tests. The planes of planar randomly distributed fibres were parallel (hereafter referred as Sigrafil_I) and perpendicular (hereafter referred as Sigrafil_II) to the longitudinal axis of the sample (identical to loading direction). Samples were deformed at an initial strain rate of $8.3 \cdot 10^{-5} \mathrm{~s}^{-1}$ over the temperature range from room temperature up to $300{ }^{\circ} \mathrm{C}$. The temperature in the furnace was kept with an accuracy of $\pm 2^{\circ} \mathrm{C}$.

Figure 7 [11] shows the true stress-true strain curves for AX41+Sigrafil_II deformed at different temperatures. It can be seen that the flow stress decreases with increasing testing temperature. At and above $200{ }^{\circ} \mathrm{C}$, the work hardening rate is decreasing with strain and temperature. Similar deformation behaviour was observed for AX41+Sigrafil_I [11]. Some dynamic recovery occurs. The

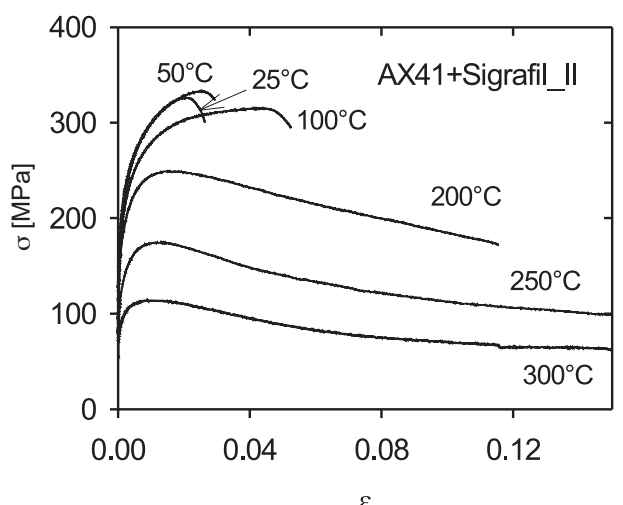

Fig. 7 The true stress-true strain curves of AX41+Sigrafil II deformed at different temperatures; the planes of planar distributes graphite fibres were perpendicular to the tensile axis.

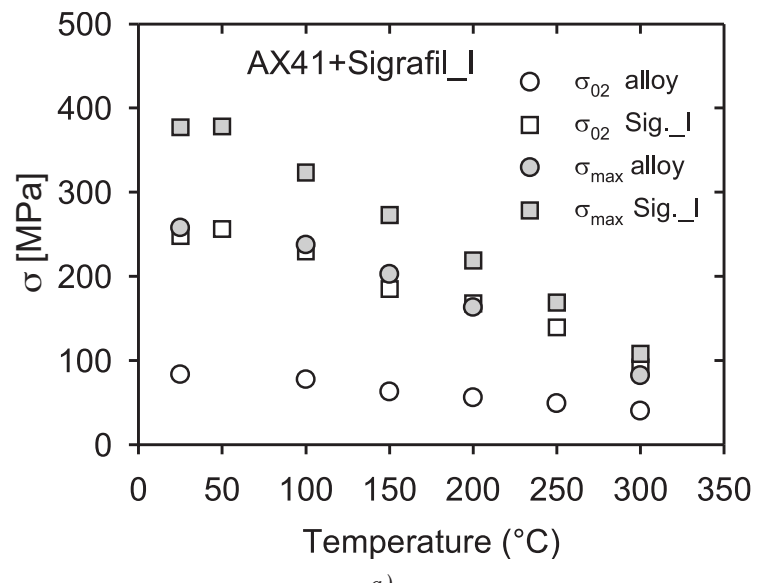

temperature variations of the yield stress, $\sigma_{02}$, and maximum stress, $\sigma_{\max }$, are shown in Fig. 8a for AX41+ Sigrafil_I and in Fig 8b for AX41+Sigrafil_II. A rapid decrease of both the stresses with increasing testing temperature for AX41+Sigrafil_I is obvious whereas the yield stress of AX41+Sigrafil_II decreases very slowly with temperature up to about $200{ }^{\circ} \mathrm{C}$ and then a rapid decrease is observed. It is necessary to note the differences in the values of $\sigma_{02}$ and $\sigma_{\max }$ for the composites with different orientation of the planar fibre distribution to the loading direction.

It is expected that new promising materials may be produced when nanosized ceramic particles are added and distributed in $\mathrm{Mg}$ matrices with fine or ultrafine grains. Materials used in this review were ultrafine-grained $\mathrm{Mg}$ (hereafter UFG-Mg), UFG-Mg reinforced with 3 vol.\% of graphite, and $\mathrm{Mg}$ with a mean grain size of about $20 \mu \mathrm{m}$ (hereafter $\mu-\mathrm{Mg}$ ) reinforces with either 3 vol.\% of $\mathrm{Al}_{2} \mathrm{O}_{3}$ (alumina) or $3 \mathrm{vol}$ \% of $\mathrm{ZrO}_{2}$ (zirconia) nanoparticles (with a mean grain of $14 \mathrm{~nm}$ ). Tensile tests were performed in an Instron testing machine at temperatures between 20 and $300{ }^{\circ} \mathrm{C}$ at a constant crosshead speed giving an initial strain rate of $6.2 \times 10^{-5} \mathrm{~s}^{-1}$. Uniaxial compression tests were carried out at a constant crosshead speed giving an initial strain rate of $1.4 \times 10^{-4} \mathrm{~s}^{-1}$.

The temperature dependences of the yield stress and maximum stress obtained for UFG-Mg and UFG-Mg+3 vol.\% of graphite $(200 \mathrm{~nm})$ are presented in Figs. 9 and 10, respectively. Specimens of microcrystalline magnesium reinforced with $\mathrm{ZrO}_{2}$ and $\mathrm{Al}_{2} \mathrm{O}_{3}$ nanoparticles were deformed in tension [12]. At temperatures above $100{ }^{\circ} \mathrm{C}$, the work hardening rate is close to zero; a dynamic balance between hardening and softening. The flow stresses for $\mu-\mathrm{Mg}+3 \mathrm{n}-$ $\mathrm{Al}_{2} \mathrm{O}_{3}$ are higher than those for $\mu-\mathrm{Mg}+3 \mathrm{n}-\mathrm{ZrO}_{2}$ at the same testing temperature. Figure 11 shows the temperature variation of the yield stress for microcrystalline $\mathrm{Mg}$ reinforced with zirconia and alumina nanoparticles. The difference in the yield stress between both materials deformed at room temperature is about $100 \mathrm{MPa}$, whereas the differences in the yield stress values at and above $200^{\circ} \mathrm{C}$ are small. On the other hand, the elongations to failure of $\mu-\mathrm{Mg}+3 \mathrm{n}-\mathrm{ZrO}_{2}$ are higher than those of $\mu-\mathrm{Mg}+3 \mathrm{n}-\mathrm{Al}_{2} \mathrm{O}_{3}$. Similar dependences of

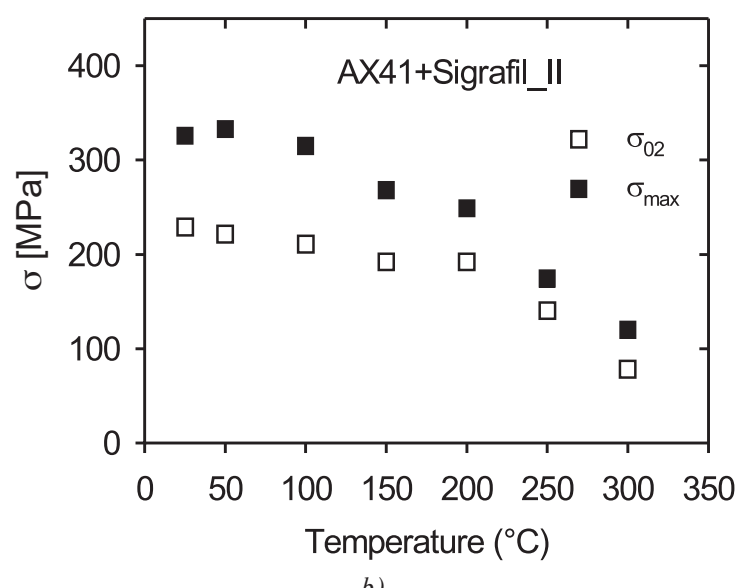

b)

Fig. 8 Temperature variation of the yield stress and maximum stress of (a) AX41+Sigrafil I

(the planes of graphite fibres were parallel to the tensile axis) and (b) AX41+Sigrafil II 


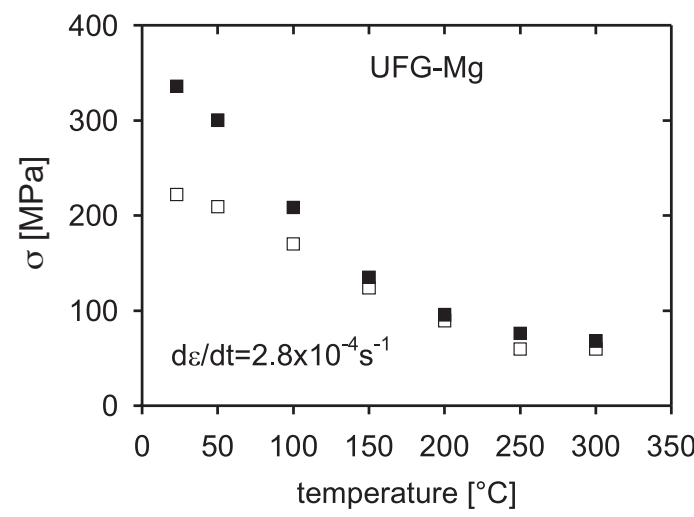

Fig. 9 Temperature dependence of the yield stress and maximum stress of ultrafine-grained magnesium.

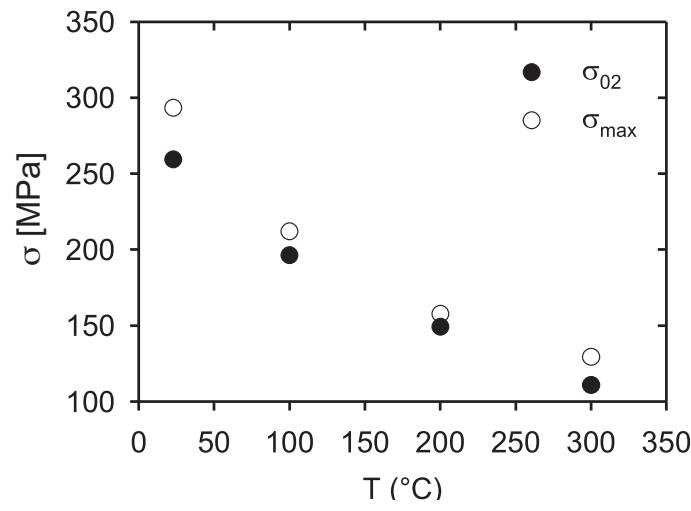

Fig. 10 Temperature dependence of the yield stress and maximum stress of ultrafine-grained magnesium reinforced with 3 vol.\% of graphite particles $(200 \mathrm{~nm})$

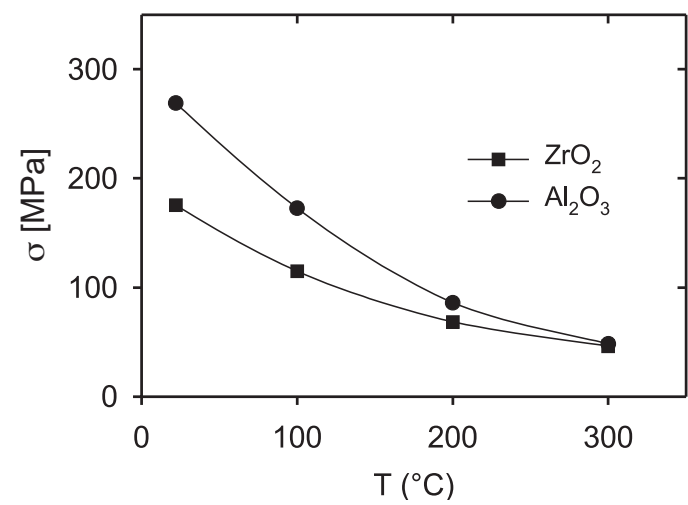

Fig. 11 Temperature dependence of the yield stress of microcrystalline magnesium reinforced with 3 vol.\% of $\mathrm{ZrO}_{2}$ and 3 vol.\% of $\mathrm{Al}_{2} \mathrm{O}_{3}$

the yield stress on the testing temperature were observed for $\mu-\mathrm{Mg}$ and in $\mu-\mathrm{Mg}+1 \mathrm{n}-\mathrm{Al}_{2} \mathrm{O}_{3}[12]$. Note the high values of yield stress for magnesium reinforced with 3 vol.\% of nanoparticles.

\section{Discussion}

The deformation behaviors of magnesium alloys and magnesium-based composites are significantly influenced by testing temperature. In order to estimate the deformation mechanisms, the understanding of the effects of deformation temperature and strain on the stress flow is necessitated. It has been found that any restoration processes affect the shape of the true stress-true strain curves. It is expected that both components of the flow stress are a function of strain and temperature.

Analysis of stress relaxation tests indicates that recovery process and dislocation motion are thermally activated processes. The both stress components were determined at different temperatures. Figure 12 [8] shows a part of true stress-true strain curve for AX41 alloy deformed in compression at room temperature. The points indicate the stresses at which the SR tests were performed. The internal stress and the effective stress components are also depicted. It is obvious that the internal stress is a substantial contribution to the applied stress. Similar dependences were obtained e.g. for AJ51

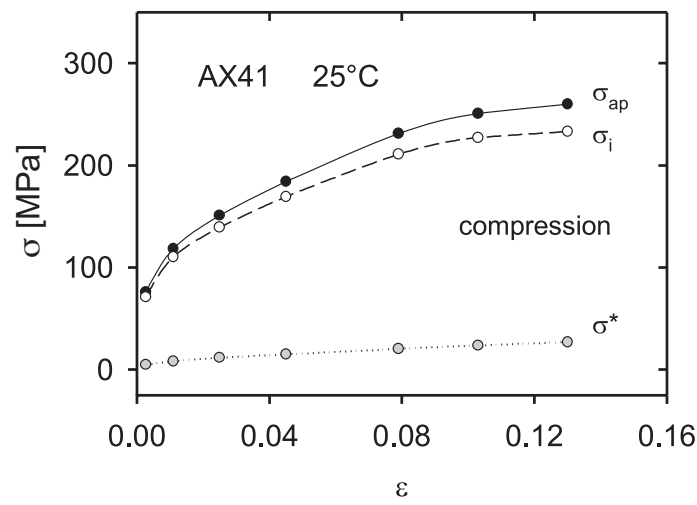

Fig. 12 A part of the true stress-true strain curve of AX41 deformed in compression at room temperature. The points on the curve indicate the stresses at which the SR tests were performed. The both components of the applied stress are shown as a function of strain

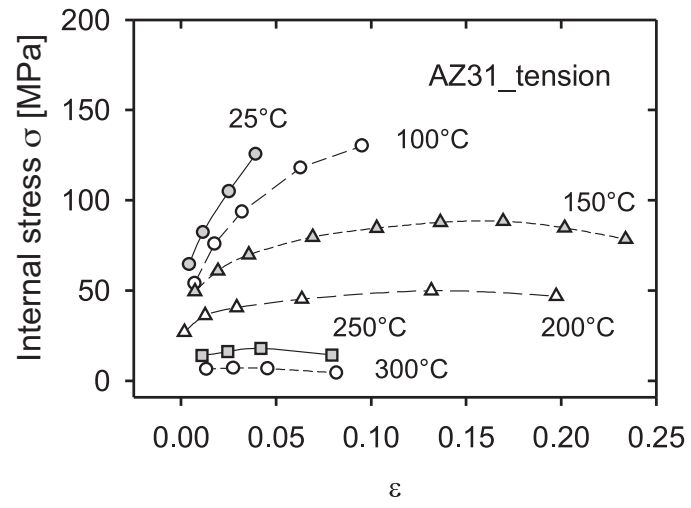

Fig. 13 The internal stress of AZ31 as a function of strain at different testing temperatures 
and AZ31. The value of the internal stress depends on the testing temperatures. The values of the internal stress for AZ31 alloy samples are plotted against strain in Fig. 13. A decrease in the internal stress component with increasing test temperature can be seen. It is well-known that the stored dislocations contribute to the strain hardening. Therefore, the observed decrease in the internal stress with temperature indicates a decrease in the total dislocation density - see Eq. (2). The moving dislocations can cross slip and after cross slip they cannot be only stored. They may annihilate, which causes the decrease in the dislocation density. At higher temperatures, the moving dislocations can also climb. The activity of cross slip and climb increases with increasing temperature. This means that the total dislocation density decreases with increasing temperature. It has been reported [8] that the internal stress/applied stress ratio decreases significantly with increasing temperature independent of the deformation mode (the values of the ratio for compression deformation are practically the same as for tension).

The apparent activation volume estimated using Eq. (8) depends on the applied stress and testing temperature. Apparent (experimental) activation volume estimate in experiments with polycrystals is proportional to the dislocation activation volume, $V_{d}$, as

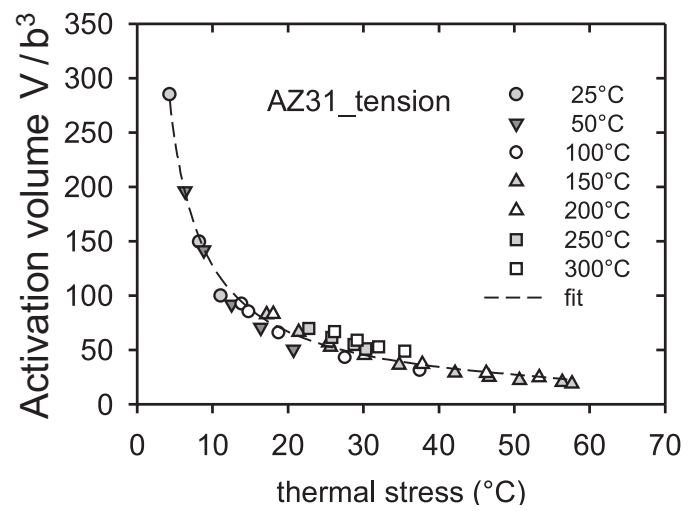

Fig. 14 Activation volume plotted against the thermal stress estimated at various testing temperatures

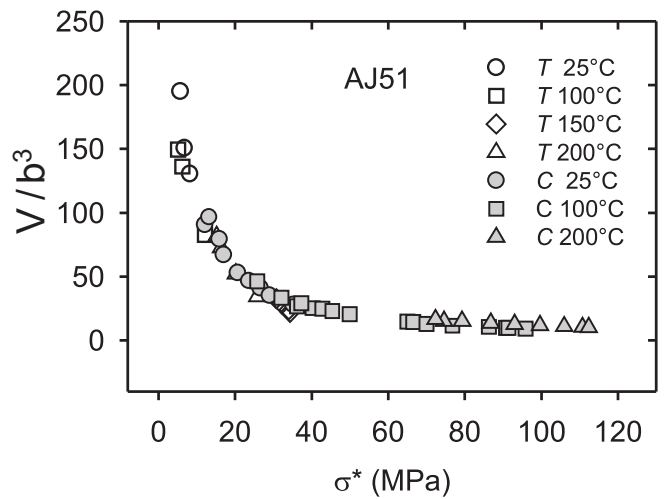

Fig. 15 Activation volume plotted against the thermal stress for AJ51 estimated at different deformation temperatures in compression and tension
$V=(1 / \Psi) V_{d}$, where $\Psi$ is the Taylor factor. Usually, the values of activation volume are given in $b^{3}$, which allows their comparison with processes responsible for the thermally activate dislocation motion. The apparent activation volume for AZ31 alloy is a function of the effective stress independently of the testing temperature as shown in Fig. 14. Apparent activation volumes for AJ51 and AJ91 alloys estimated for four deformation temperatures in tensile $(\mathrm{T})$ and compression $(\mathrm{C})$ tests are plotted against the effective (thermal) stress in Figs. 15 and 16 [8]. All values appear to lie on one line, "master curve". In order to analyse the dependences, we will assume an empirical relation between the Gibbs enthalpy $\Delta G$ and the effective stress, $\sigma^{*}$, suggested by Kocks et al. [13] in the following form:

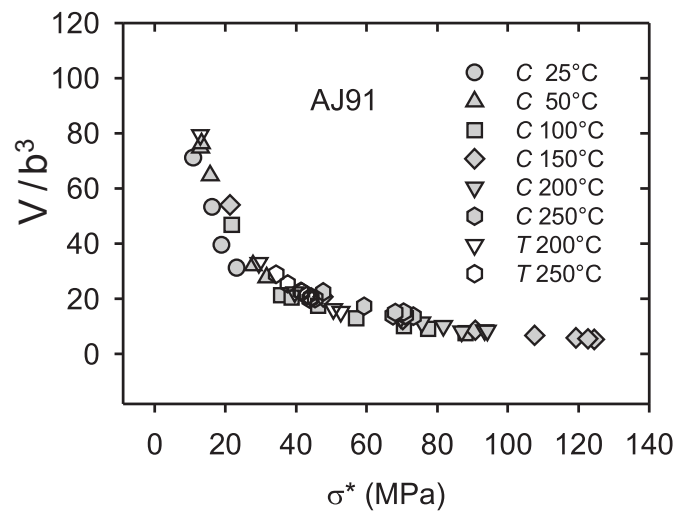

Fig. 16 Activation volume plotted against the thermal stress for AJ91 estimated at different deformation temperatures in compression and tension

$$
\Delta G=\Delta G_{0}\left[1-\left(\frac{\sigma^{*}}{\sigma_{0}^{*}}\right)^{p}\right]^{q}
$$

where $\Delta G_{0}$ and $\sigma_{0}^{*}$ are Gibbs enthalpy at zero stress and the effective stress at $0 \mathrm{~K}$. It follows:

$$
\sigma^{*}=\sigma_{0}^{*}\left[1-\left(\frac{k T}{\Delta G_{0}} \ln \frac{\dot{\varepsilon}_{0}}{\dot{\varepsilon}}\right)^{1 / q}\right]^{1 / p}
$$

where $p$ and $q$ in Eqs. (6) and (7) are phenomenological parameters reflecting the shape of a obstacle profile $k$ is the Boltzmann constant, $T$ is the absolute temperature, $\dot{\varepsilon}$ is the strain rate and $\dot{\varepsilon}_{0}$ is a pre-exponential factor. The possible ranges of values $p$ and $q$ are limited by the conditions $0<p \leq 1$ and $1 \leq q \leq 2$. Ono [14], suggested that Eq. (17) with $p=1 / 2, q=3 / 2$ describes a barrier shape profile that fits many predicted barrier shapes. Equation (7) can be rewritten

$$
\dot{\varepsilon}=\dot{\varepsilon}_{0} \exp \left[-\frac{\Delta G_{0}}{k T}\left(1-\left(\frac{\sigma^{*}}{\sigma_{0}^{*}}\right)^{p}\right)^{q}\right] .
$$

The dependence of the activation volume on the effective stress can be expressed as

$$
V=k T \frac{\partial \ln \dot{\varepsilon} / \dot{\varepsilon}_{0}}{\partial \sigma^{*}}=\frac{\Delta G_{0} p q}{\sigma_{0}^{*}}\left[1-\left(\frac{\sigma^{*}}{\sigma_{0}^{*}}\right)^{p}\right]^{q-1}\left(\frac{\sigma^{*}}{\sigma_{0}^{*}}\right)^{p-1} .
$$


The values of the activation volume should lie at the curve given by Eq. (9). The fit of the experimental values of Eq. (9) see Figs. (15) and (16) - gives for the activation enthalpy $\Delta G_{0}=$ $=0.95 \pm 0.05 \mathrm{eV}$ for AJ51 and $\Delta G_{0}=1.00 \pm 0.05 \mathrm{eV}$ for AJ91 Similar values of the activation enthalpy were estimated for all alloy studied.

The values of the activation volume and the activation enthalpy may help to identify thermally activated process considering some of the common short range barriers to dislocation motion [15]. We should consider that a rapid decrease in the internal stress with increasing temperature indicates that observed softening during deformation is connected with dynamic recovery.

It is well-known that the main deformation mode in magnesium and magnesium alloys with hcp structure is basal glide system with dislocations of the Burgers vector $\langle a\rangle=1 / 3$ [1120]. The secondary conservative slip may be realised by the $\langle a\rangle$ dislocations on prismatic and pyramidal of the first order. Couret and Caillard $[16,17]$ using TEM showed that the screw dislocations with the Burgers vector of $1 / 3$ [1120] in magnesium are able to glide on prismatic planes and their mobility is much lower than the mobility of edge dislocations. They concluded that the deformation behaviour of magnesium over a wide temperature range is controlled by thermally activated glide of those screw dislocation segments A single controlling mechanism was identified as the Friedel-Escaig cross slip mechanism. This mechanism assumes dissociated dislocations on compact planes, like (0001), that joint together along a critical length $L_{r}$ producing double kinks on non-compact planes. Therefore, the activation volume is proportional to the critical length between two kinks. Amadieh et al. [18] found for the activation volume of the Friedel-Escaig mechanism a value of $70 \mathrm{~b}^{3}$. Prismatic slip was also observed by Koike and Ohyama [19] in deformed AZ61 sheets. The activation of the prismatic slip and subsequent annihilation of the dislocation segments with the opposite sign are probably the main reason for the observed internal stress decrease. The double cross slip may be a thermally activated process controlling the dislocation velocity.

The number of independent slip systems in the basal plane is only two. Thus, the von Mises requirement for five independent deformation modes to ensure a reasonable deformability of magnesium alloy polycrystals is not fulfilled. Twinning and the activity of non-basal slip is required. From activities of non-basal slip systems, motion of dislocations with $\langle c+a\rangle$ Burgers vector in the second-order pyramidal slip systems is expected. The critical resolved shear stress (CRSS) for non-basal slip systems at room temperature is higher by about a factor 100 than the CRSS for basal slip. The CRSS for non-basal slip decreases rapidly with increasing temperature. It means that the activity of a non-basal slip system increases with increasing temperature. It is worth mentioning that Mathis et al. [20], who studied the evolution of different types of dislocations with temperature in $\mathrm{Mg}$ using X-ray diffraction, found that at higher temperatures the fraction of $\langle c+a\rangle$ dislocations increases at a cost of $\langle a\rangle$ dislocations. The total dislocation density decreases with increasing temperature. The glide of $\langle c+a\rangle$ dislocations may affect the deformation behaviour of magnesium alloys.

The shape of the true stress-true strain curves (Figs. 1-4) indicates that the flow stress and strain hardening and softening is influenced by the testing temperature - at temperatures above about $200{ }^{\circ} \mathrm{C}$, the strain hardening is very close to zero. From the dislocation theory point of view, this deformation behaviour may be explained assuming changes in deformation mechanisms. At temperatures below about $200{ }^{\circ} \mathrm{C}$, strain hardening is caused by multiplication and storage of dislocations. Above about $200{ }^{\circ} \mathrm{C}$, there is not only storage of dislocations during straining leading to hardening but also annihilation of dislocations leading to softening. The intensity of the latter is highly dependent on temperature. A dynamic balance between hardening and softening may take place at higher temperatures. The activity of non-basal slip systems has to play an important role in both hardening and recovery processes in magnesium alloys. The glide of $\langle c+a\rangle$ dislocations may be responsible for an additional work hardening because of the development of several systems of immobile or sessile dislocations. Different reactions between $\langle a\rangle$ basal dislocations and $\langle c+a\rangle$ pyramidal dislocations can occur [21-23]. Glissile (glide) $\langle c+a\rangle$ dislocations can interact with $\langle a\rangle$ dislocations - immobile $\langle c\rangle$ dislocations may arise within the basal plane according to the following reaction:

$$
{ }_{3}^{1}\langle 2 \overline{1} \overline{1} 3\rangle+{ }_{3}^{1}\langle\overline{2} 110\rangle \rightarrow\langle 0001\rangle .
$$

Another reaction that employs the basal $\langle a\rangle$ dislocations yields a sessile $\langle c+a\rangle$ dislocation

$$
{ }_{3}^{1}\langle 2 \overline{1} \overline{1} 3\rangle+{ }_{3}^{1}\langle\overline{1} 2 \overline{1} 0\rangle \rightarrow{ }_{3}^{1}\langle 11 \overline{2} 3\rangle .
$$

Finally, a combination of two glissile $\langle c+a\rangle$ dislocations gives rise to a sessile dislocation of $\langle a\rangle$ type that liess along the intersection of the second order pyramidal planes according to the following reaction:

$$
{ }_{3}^{1}\langle 2 \overline{1} \overline{1} 3\rangle+{ }_{3}^{1}\langle\overline{1} 2 \overline{1} \overline{3}\rangle \rightarrow{ }_{3}^{1}\langle 11 \overline{2} 0\rangle .
$$

Different dislocation reactions may produce both sessile and glissile dislocations. Production of sessile dislocations increases the density of the forest dislocations that are obstacles for moving dislocations. Therefore, an increase in the flow stress with straining follows, which is observed in the experiment. On the other hand, screw components of $\langle c+a\rangle$ (and also $\langle a\rangle$ ) dislocation may move to the parallel slip planes by double cross slip and they can annihilate - the dislocation density decreases, which leads to softening. One has to consider that twins and grain boundaries are also obstacles for moving dislocations in polycrystalline materials. Dislocation pile-ups are formed at the grain boundaries. The stress concentrations at the head of pile-ups contribute to initiations of the activity of the pyramidal slip systems. Another possible source mechanism for $\langle c+a\rangle$ dislocations was proposed by Yoo et al. [24]. The scenario described above can help in understanding the deformation behaviour of magnesium alloy over a wide temperature range. 
The increase in the elongation to failure with increasing temperature can be also explained by an increase in the activity of non-basal slip systems.

The addition of the reinforcing phase substantially increases the yield stress of $\mathrm{Mg}$ alloys as shown above. Fibres and particles in the matrix act as obstacles for moving dislocations in the slip plane. From figures a significant effect of fibres and/or particles on the yield stress and deformation behaviour at low temperatures (below about $200{ }^{\circ} \mathrm{C}$ ) and a decreasing effect of the reinforcing phase at higher temperatures can be seen. The main contributions to the yield stress are load transfer and enhanced dislocation density. The analysis - see [25, 26] - showed that the load transfer from matrix to fibres (particles) depends on the reinforcement volume fraction. As to the enhanced dislocation density, important contributions are the density of newly generated dislocations due to thermal stresses and the density of dislocations geometrically necessarily created because of strong strain gradients. It is widely accepted that Orowan strengthening is not significant for metal matrix composites.

\section{Conclusions}

The mechanical properties and strain hardening effects of magnesium alloys decrease with increasing testing temperature. The increase of the activity of non-basal slip systems with temperature may be responsible for softening. The interactions between dislocations in the non-basal slip system and those in basal slip system cause not only the formation of sessile dislocation leading to hardening but also annihilation of dislocations leading to softening.

\section{Acknowledgements}

The authors would like to dedicate this paper to Prof. Ing. Otakar Bokuvka, Ph.D., at the occasion of his 65 th birthday. This work was partly supported by the Grant Agency of the Academy of Sciences of the Czech Republic under Grant IAA201120902. A part of this work was financed by the Ministry of Education, Youth and Sports of the Czech Republic under the Research Project 1M2560471601 "Eco-centre for Applied Research of Nonferrous Metals".

\section{References}

[1] MORDIKE, B.L., LUKAC, P.: Magnesium Technology, Eds. Fridrich, H. E., Mordike, B. L., Berlin, Springer, 2005.

[2] VALIEV, R. Z., LANGDON, T. G.: Prog. Mater. Sci., No. 51, 2006, 881.

[3] CAILlaRD, D., MARTIN, J. L.: Thermally Activated Mechanisms in Crystal Plasticity, Amsterdam, Pergamon, 2003.

[4] DOTSENKO, V. I.: Phys. Stat. Sol. (b), 93, 1979, 11.

[5] FELTHAM, P.: Phys. Stat. Sol. (a), 3, 1963, 1340

[6] LI, J. C. M.: Canad. J. Phys., 45, 1967, 493.

[7] LI, J. C. M.: Scripta Metall., 15, 1981, 935.

[8] TROJANOVA, Z., LUKAC, P.: Int. J. Mater. Res., 100, 2009, 270.

[9] BALIK, J., LUKAC, P., BOHLEN, J., KAINER, K. U.: Kovove mater., No. 45, 2007, 135.

[10] MATHIS, K., MUSSI, A., TROJANOVA, Z., LUKAC, P., RAUCH, E.: Kovove mater., No. 41, 2003, 293.

[11] TROJANOVA, Z., LUKAC, P.: Int. J. Mater. Res., 100, 2009, 399.

[12] LUKAC, P., TROJANOVA, Z.: Introduction to Nanotechnology, Eds. Dusza, J., Drageva, I., Sofia, Herom Press, 2006.

[13] KOCKS, U. F., ARGON, A. S., ASHBY, M. F.: Prog. Mater. Sci., 19, 1975, 1.

[14] ONO, K.: J. Appl. Phys., 39, 1968, 1803.

[15] EVANS, A. G., RAWLINGS, R. D.: Phys. Stat. Sol. (a), 34, 1969, 9.

[16] COURET, A., CAILLARD, D.: Acta Metall., 33, 1985, 1447.

[17] COURET, A., CAILlARD, D.: Acta Metall., 33, 1985, 1455.

[18] AMADIEH, A., MITCHELL, J., DORN, J.E.: Trans. AIME, 233, 1965, 1130.

[19] KOIKE, J., OHYAMA, R.: Acta Mater., 53, 2005, 1963.

[20] MATHIS, K., NYILAS, K., AXT, A., DRAGOMIR-CERMATESCU, I., UNGAR, T., LUKAC, P.: Acta Mater., 52, $2004,2889$.

[21] LUKAC, P.: Czech. J. Phys., 31, 1981, 135.

[22] LUKAC, P.: Czech. J. Phys., 35, 1985, 275.

[23] LUKAC, P., MATHIS, K.: Kovove mater., No. 40, 2002, 281.

[24] YOO, M. H., AGNEW, S. R., MORRIS, J. R., HO, K. M.: Mater. Sci. Eng. A, 321, 2001, 87.

[25] LUKAC, P., TROJANOVA, Z.: Communications - Scientific Letters of the University of Zilina, Vol. 11, No. 1, $2009,5$.

[26] TROJANOVA, Z., SZARAZ, Z, GARTNEROVA, V.: Communications - Scientific Letters of the University of Zilina, Vol. 11, No. $1,2009,10$. 